\title{
Musealizar la memoria de las víctimas
}

\section{Giving the Memory of the Victims a museum-like status}

\author{
ELENA ESCRIBANO GONZÁLVEZ \\ Universidad de Murcia \\ leg21385@um.es
}

Resumen: Este artículo tiene como objetivo principal acotar la tendencia cultural de musealizar la memoria de las víctimas, analizando, dentro de los espacios culturales, los llamados museos memoriales y lugares de conciencia. De forma sintética se muestran algunos ejemplos de países que han dado tratamiento a la musealización de esta modalidad de memoria para, posteriormente, profundizar en las confrontaciones y procesos sociales que genera la representación de este patrimonio memorial, definir los lenguajes y formatos para su trasmisión y exponer una lectura crítica de la trayectoria experimentada en España.

Palabras clave: Víctimas, memoria, memoriales, museos conmemorativos, España.

\begin{abstract}
The main objective of this article is to limit the cultural tendency to giving the memory of the victims a museum-like status and to analyze, within the cultural spaces, the so called memorial museums and places of conscience. In summary, this paper presents some examples of the countries that have given this modality of memory the status of museum, in order to further deepen in the confrontation and social processes that generate the representation of this memorial heritage, to define the languages and formats for its transmission, and to expose a critical reading of the trajectory experienced in Spain.
\end{abstract}

Keywords: Victims, memory, memorials, memorials museums, Spain.

Recibido: 31 de noviembre de 2016; aceptado: 10 de mayo de 2017; publicado: 27 de marzo de 2018. Revista Historia Autónoma, 12 (2018), pp. 261-278.

e-ISSN: 2254-8726; DOI: https://doi.org/10.15366/rha2018.12.014. 


\section{Introducción}

El monumento memorial se empleó, antes de la Segunda Guerra Mundial, con funciones puramente ornamentales y funerarias; también con la intención de transmitir valores referidos al honor, valentía, unión o triunfo nacional, pero la gravedad y proporción de este acontecimiento bélico supuso un cambio de paradigma en las formas de conmemoración ${ }^{1}$. La causa principal de la transformación se debió a que los muertos ya no eran héroes militares sino, mayoritariamente, víctimas directas del conflicto, civiles inocentes exterminados cruelmente ${ }^{2}$. La conciencia de este trauma, el deseo pacifista universal y la consolidación de una sociedad cada vez más participativa y democrática hicieron posible que aquellos hechos condenables fuesen dignos de representación, exigiendo reparación, culpa y reflexión.

Las diversas tragedias del siglo xx fueron generando una obsesión cultural por la memoria, tanto en el campo académico como social, que a partir de los años 60 incrementó la construcción de monumentos y museos conmemorativos cuyos protagonistas eran víctimas del Holocausto, terrorismos, estados totalitarios... fijando las aspiraciones e intereses políticos de sus promotores y redefiniendo, también, el concepto de nación y unidad desde la experiencia común de un trauma o sacrificio, tendencia que se mantiene en las dos primeras décadas del siglo XXI.

Tras exponer sintéticamente el concepto 'memorial'y los motivos que llevan a su creación, este artículo centra su estudio en los museos conmemorativos con la intención de exponer sus posibilidades y limitaciones como complementos de enseñanza para el conocimiento y divulgación científica de la historia, fomentando la conciencia social, el desarrollo local y aperturismo político y económico. El objetivo de esta investigación es el de ajustar un patrón para la nueva categoría de "museo memorial" que aclare si son instrumentos fundamentales para el desarrollo de sociedades más cívicas y qué les lleva, en algunos casos, al fracaso o a la confrontación.

\footnotetext{
${ }^{1}$ Mosse, George L., Soldados Caídos. La transformación de la memoria de las guerras mundiales, Zaragoza, Prensas de la Universidad de Zaragoza, 2016, pp. 132-146 y 275-280.

${ }^{2}$ Velázquez Marroni, Cintia, "El museo memorial: un nuevo espécimen entre los museos de historia", en Intervención, vol. 2, 3 (2011), p. 11. «https://dialnet.unirioja.es/descarga/articulo/4947390.pdf» [consultado el 23 de marzo de 2016].
} 
1. El monumento memorial

\subsection{Agentes y modelos de memorialización}

Para comprender esta investigación es necesario diferenciar "monumento" de "memorial": las funciones del primero se limitan a perpetuar un suceso o recordar y homenajear a individuos ocupando el espacio público o privado mediante diversas disciplinas artísticas. Por su parte, el memorial es un tributo a la muerte y responde al objetivo de homenajear a los fallecidos como consecuencia de violencias o injusticias sociales (o a sus familiares) con la finalidad de ofrecer un lugar para el duelo que compense el vacío por la pérdida de las víctimas y sane a la sociedad bajo los lemas del "no olvido" y "nunca más".

El desarrollo de la tecnología y los medios de comunicación ha proporcionado a los ciudadanos numerosos canales para, de manera libre y espontánea, intentar apropiarse del espacio físico y virtual, dando lugar a memoriales: oficiales, no oficiales, públicos, privados, permanentes o efímeros. Estos instan al Estado y a la sociedad a hacerse cargo de un problema arrastrado por el silencio y el tiempo y a la vez inauguran un proceso de cambio social que ayuda a asumir el presente, a luchar contra la ignorancia del pasado y reconocer la culpa. La conservación y difusión de la memoria se ofrece, así, como instrumento para el asentamiento de valores comunes con vistas al futuro ${ }^{3}$.

En la construcción de estos elementos conmemorativos inciden variables como la distancia temporal con el hecho histórico o el cambio generacional. Los conflictos del pasado suelen estar presentes sobre todo si los escenarios de cambio político favorecen el debate y la multiplicidad de discursos sobre el pasado y, por ende, la fragmentación de la memoria ${ }^{4}$ ya sea en un mismo colectivo o incluso confrontando memorias dominantes entre países, como sucede en EEUU y Corea respecto a la Guerra Fría entre 1950-53. Pero debemos aclarar que no todo proceso doloroso del pasado se inscribe en el espacio público y los que lo logran a veces omiten datos o silencian voces. La urgencia con la que se erigen, intencionalidad y selección de memoria confunden en ocasiones acerca de su propósito.

Como explica Coro Rubio, aunque la proliferación de memoriales pretenda legitimar la identidad colectiva de una nación, "la multiplicación de los vínculos con el pasado que esos memoriales representan $[\ldots]$ no les convierte en un instrumento de recuperación de la historia, a

\footnotetext{
${ }^{3}$ González Galeotti, Juana Victoria, Monumentos y memoria contemporáneos: un acercamiento a la estética del recuerdo, tesis doctoral, Universidad Autónoma de Barcelona, 2010, p. 9. «http://www.recercat.cat/bitstream/ handle/2072/48869/Treball\%20de\%20Recerca\%20VG.pdf?sequence=1» [consultado el 24 de marzo de 2016].

${ }^{4}$ Halbwachs, Maurice, La memoria colectiva, Zaragoza, Prensas Universitarias de Zaragoza, 2004, p. 86.
} 
pesar de que sean presentados como tales" .Y es que debemos matizar que "memoria" e "historia" no son lo mismo: como ya explicaba Pierre Nora, la "memoria" evoluciona permanentemente y es vulnerable a la manipulación y al tiempo, está abierta al recuerdo y a la amnesia y puede ser individual o colectiva. Sin embargo, la "historia" es la reconstrucción del pasado, requiere análisis y discurso crítico y desconfía de la memoria ${ }^{6}$. Por ello, los lugares donde se inscribe la memoria son un modo de compartir y definir los recuerdos, intentando cuadrarlos en el pasado, afianzándolos para que la historia no los olvide, perpetuando la conciencia histórica y colectiva ${ }^{7}$.

A partir de lo expuesto interesa mostrar algunos modelos de memorialización empleados por países que han destacado en la construcción de memoriales, presentando los diferentes contextos políticos e institucionales y las correspondientes vicisitudes que rodearon los procesos de recuperación de la historia y la memoria.

Es inevitable encabezar este análisis con el ejemplo de Alemania, dada su larga trayectoria en los trabajos de la memoria y el complejo debate experimentado hasta obtener el actual tratamiento sobre su pasado ${ }^{8}$. La derrota en la Segunda Guerra Mundial condenó a Alemania a la división en dos espacios diferenciados y ocupados por los aliados y sumió a la mayoría de su población en una posición de desvalorización social y política abocados al sentimiento de culpa por los crímenes del nazismo cuando no a la amnesia. Las nuevas generaciones intentarán comprender lo sucedido brotando así las primeras iniciativas apoyadas por ONGs, que cristalizaron en monumentos memoriales idealizados a ambos lados del Muro de Berlín, pero que tergiversaban la historia y restaban credibilidad. No fue hasta la década de los 80 cuando el Holocausto y el genocidio tuvieron realmente un reconocimiento oficial por parte de la Alemania Occidental. Un momento catalizador ocurrió en 1985 con el discurso del presidente de la República Federal de Alemania, Richard Von Weizsäcker, con motivo del 40 aniversario del fin de la Segunda Guerra Mundial, en el que manifestó que Alemania el 8 de mayo de 1945 había sido liberada y no vencida, encaminando al país a encontrar la manera de tratar la historia como una víctima más. Tras la caída del Muro en 1989 y el reconocimiento oficial e indemnización al pueblo judío, la Alemania unificada procedió a profundizar en la identidad democrática, no sin dificultades dada la diferente tradición de culturas públicas de memoria desarrolladas en la antigua Alemania Federal y la Alemania Oriental ${ }^{9}$. Pero, tras la unificación, Alemania cuenta con un marco institucional fuerte y recursos económicos más que suficientes

\footnotetext{
${ }^{5}$ Rubio Pobes, Coro, "Los rostros de la memoria. El fenómeno memorialista en el mundo actual y sus usos políticos", en Historia y Política, 35 (2016), p. 364. DOI: http://dx.doi.org/10.18042/hp.35.14. «http://recyt.fecyt. es/index.php/Hyp/article/view/50910/31100» [consultado el 22 de enero de 2017].

${ }^{6}$ Nora, Pierre, Pierre Nora en les lieux de mémoire, Santiago, Trilce, 2009, pp. 19-38.

${ }^{7}$ Lowenthal, David, El pasado es un país extraño, Madrid, Akal, 1998, pp. 310-312.

${ }^{8}$ Para profundizar en esta problemática ver Traverso, Enzo, El pasado. Instrucciones de uso. Historia, memoria y política, Madrid, Marcial Pons, 2000, en especial el capítulo 5, "Los dilemas de los historiadores alemanes", pp. 81-92.

${ }^{9}$ Moeller, Robert G., "War Stories: The Search for a Usable Past in the Federal Republic of Germany", en The American Historical Review, vol. 101, 4 (1996), p. 1041. «http://www.jstor.org/stable/2169632» [consultado el 10 de abril de 2017]. DOI: https://doi.org/10.2307/2169632.
} 
para garantizar desde distintos ámbitos, sus políticas memoriales ${ }^{10}$. Hoy sigue centrada en reforzar la inclusión de colectivos excluidos o que no se habían sentido representados en los diferentes memoriales gestionados por el Estado, como los gitanos o los homosexuales ${ }^{11}$, y en aminorar el sentimiento encontrado de quienes aún les resulta difícil aceptar una representación memorial compartida entre alemanes y judíos ${ }^{12}$.

Con un fin de promover la reivindicación nacional y el restablecimiento de la memoria del país, encontramos el caso de Lituania, que tras recuperar su independencia del poder soviético y por orden del Consejero de Cultura y Educación y del Presidente de la Unión de Presos y Deportados, estableció el Museo de las Víctimas del Genocidio en 1992, situado en las antiguas oficinas de la $\mathrm{KGB}^{13}$. Este museo se levantó contra la memoria oficial generada por la URSS tras la Segunda Guerra Mundial, que había silenciado la existencia de lituanos soviéticos colaboracionistas con el fascismo y dejado ausentes del recuerdo a la mitad de las víctimas judías ${ }^{14}$.

Muy distinta fue la trayectoria seguida por países latinoamericanos postdictatoriales como Argentina y Chile, donde no fueron los organismos públicos ni el Estado los agentes protagonistas de dinamización de políticas memoriales, sino la sociedad civil, que representó un papel fundamental en la inicial recuperación de la memoria y el esclarecimiento de las violaciones de derechos humanos (DDHH) y crímenes dictatoriales que permanecían ocultos, silenciados y negados ${ }^{15}$.

En Argentina fueron los grupos de familiares de víctimas y supervivientes del régimen militar de Rafael Videla (1976-1983), apoyados por organizaciones de DDHH, quienes tomaron las riendas de un modo inmediato tras recuperarse la democracia gestionando y financiando de

\footnotetext{
${ }^{10}$ Birle, Peter et al. (eds.), Memorias urbanas en diálogo: Berlín y Buenos Aires, Buenos Aires, Buenos Libros, 2010. «https://mx.boell.org/sites/default/files/memorias urbanas en_dialogo.pdf» [consultado el 22 de marzo de 2016]. Los rasgos especiales de la cultura del recuerdo en Alemania, en Lutz, Thomas, "La relación dialéctica entre la reflexión internacional y nacional sobre los crímenes del régimen nazi y el reconocimiento de las víctimas: el ejemplo de Alemania”, en Guixé i Coromines, Jordi (ed.), Past and Power. Publice Policies on Memory. Debates, from Global to Local, Barcelona, Edicions de la Universitat de Barcelona y European Observatory on Memories, 2016, pp. 350-366.

${ }^{11}$ Los homosexuales fueron el último grupo de víctimas en ser reconocido, en 1985, y no fue hasta el 2002 que el gobierno alemán anuló las sentencias nazis (anteriores a 1945; las posteriores nunca han sido anuladas) y pidió disculpas a la comunidad gay. En: "Memoria y tolerancia recuerda homosexuales perseguidos bajo régimen nazi". «http://www.enlacejudio.com/2011/05/20/memoria-y-tolerancia-recuerda-homosexuales-perseguidos-bajoregimen-nazi/» [consultado el 30 de abril de 2016].

${ }^{12} \mathrm{Al}$ respecto se ha afirmado que "no puede existir un simple 'memorial' sobre el nacionalsocialismo, igual que no puede haber una única narrativa del Tercer Reich", en Toro, Francesc Miquel de, "Políticas de memorialización y victimización en Alemania: la Neue Wache y el espacio memorial (1870-1993)", en Ayer, 100 (2015), p. 227.

${ }^{13}$ Santacana i Mestre, Joan y Francesc Xavier Hernández Cardona, Museos de historia. Entre la taxidermia y el nomadismo, Gijón, Ediciones Trea, 2011, pp. 112-113.

${ }^{14}$ La confrontación de memorias desde la II Guerra Mundial en el antiguo espacio de dominio soviético, y el surgimiento (tras el declive socialista de 1989) de distintos paradigmas en torno al recuerdo y su narrativa, y la erección institucional de complejos memorialísticos en toda Europa centroriental, en Núñez Seixas, Xosé Manoel, “El Frente del Este (1939-1945): ¿Un lugar de memoria transnacional?”, en Rodrigo, Javier (ed.), Políticas de la Violencia. Europa siglo XX, Zaragoza, Prensas de la Universidad de Zaragoza, 2014, pp. 241-282.

${ }^{15} \mathrm{La}$ evolución de la lucha por la memoria de las víctimas, su concreción memorialística y la instauración de políticas públicas del pasado en los países del Cono Sur (muy duramente castigados por sus respectivas dictaduras), en Wasserman, Claudia, "Las políticas del pasado en América Latina: la responsabilidad del historiador y las artimañas de la memoria”, en Guixé i Coromines, Jordi (ed.), Past and Power... op. cit., pp. 322-336.
} 
manera privada cada iniciativa por la memoria. Actualmente, a 40 años del golpe de Estado, las políticas culturales tienen más apoyo institucional, pero su desarrollo está condicionado por las limitaciones presupuestarias y continuos vaivenes políticos del país. El éxito de su cambio se debe principalmente a la veloz rehabilitación de su sistema de justicia transicional, ya que se trata del primer país del Cono Sur que derogó las leyes de Amnistía ${ }^{16}$ que habían permitido la impunidad de los perpetradores. Argentina también fue pionera en la celebración de juicios contra los responsables de las violaciones de lesa humanidad pero además, y no menos importante, por las diferentes estrategias de aperturismo cultural llevadas a cabo mediante marcos de cooperación, como por ejemplo el firmado en 1994 entre Buenos Aires y Berlín, en relación a la promoción de diferentes espacios memoriales ${ }^{17}$ : destacan la ExESMA (antigua Escuela de Mecánica de la Armada utilizada como centro clandestino de tortura y exterminio durante la dictadura), asumida como política de Estado a partir de 2003, o el Parque de la Memoria de Buenos Aires, inaugurado en 2001.

En el caso de Chile, la dictadura militar de Augusto Pinochet (1973-1990) fue derrotada por referéndum creándose una Comisión Nacional de Verdad y Reconciliación que tenía como cometido esclarecer los crímenes de la dictadura pero el resultado del "Informe Rettig” ocultó a los victimarios y, tras las disculpas oficiales del Presidente de la República, Patricio Aylwin, con la intención de dejar atrás el pasado, se fortalecieron movimientos por la memoria y los derechos humanos que lucharon contra un gobierno poco predispuesto que optaba por obstruir la justicia y borrar las marcas de terror anulando la memoria del país. Pero en 1998, el arresto de Pinochet en Londres presionó y obligó al Estado chileno a comprometerse con la petición de verdad, justicia y reparación que víctimas y familiares reclamaban desde años atrás, comenzando los trabajos de reparación y creación de espacios de memoria y generando nuevas políticas públicas. Así, y pese a lo reciente de su historia, en el año 2003 Chile reconoció oficialmente a las víctimas de la tortura y hoy cuenta con varios espacios dedicados a la memoria y a la educación entre los que destacan: el Parque por la Paz de Villa Grimaldi, antiguo centro de detención y tortura, lugar de reflexión inaugurado un año antes del arresto de Pinochet gracias a la presión que familiares y vecinos lograron con el ligero apoyo de políticos moderados; o el Museo de la Memoria y los DDHH, puesto en marcha en 2010 bajo la primera etapa de gobierno de Michele Bachelet ${ }^{18}$, con la intención de mostrar los crímenes cometidos entre 1973 y 1990.

El debate de ambos países latinoamericanos, Argentina y Chile, se centra hoy en cómo lidiar con los desacuerdos y memorias fragmentadas que tienden a quedar fuera del relato oficial;

\footnotetext{
$\overline{{ }^{16} \text { Así llamadas la }}$ Ley 23492 de 23 de diciembre de 1986, de Punto Final, en Boletín Oficial de la República Argentina, 29 de diciembre 1986, y la Ley 23521 de 4 de junio de 1987, de Obediencia Debida, en Boletín Oficial de la República Argentina, 9 de junio de 1987, anuladas por el Congreso Nacional en 2003.

${ }^{17}$ Birle, Peter et al. (Eds.), Memorias urbanas... op. cit., pp. 9-22.

${ }^{18}$ La configuración de una memoria hegemónica estatal en Chile en Garcés, Mario, "Actores y disputas por la memoria en la transición siempre inconclusa", en Ayer, 79 (2010), pp. 147-169.
} 
en definitiva, en qué debe ser recordado y cómo $^{19}$. Problemática que trasladada a España refleja su diferente trayectoria con respecto a estos países latinoamericanos ${ }^{20}$ : en efecto, la Guerra Civil marcó la evolución histórica del país, y la dictadura y sus victimarios se salvaguardaron con la impunidad proporcionada por la Ley 46/1977 de Amnistía ${ }^{21}$; al tiempo que la Transición, condicionada por el intento de golpe de estado del 23-F, el terrorismo de ETA y el miedo al recuerdo de la Guerra civil y sus consecuencias, consensuó lo que para algunos historiadores fue un "pacto del olvido" y "tiempo de silencio", no exento de debate historiográfico ${ }^{22}$, que se plasmaría a su vez en la ausencia de políticas públicas de memoria ${ }^{23}$. Y si bien comenzada la democracia, y más desde 1982 con la mayoría socialista, nada impedía a las instituciones desarrollar un marco que contribuyese al fortalecimiento de la memoria e identidad de la nación, no figuró entre sus prioridades la de rendir homenaje memorialístico a las víctimas de la Guerra Civil y el franquismo ${ }^{24}$. Con la entrada en vigor de la Constitución de 1978 se legalizó la asociación "Amical de Mauthausen" de exiliados republicanos deportados a campos nazis $\mathrm{y}$, de manera puntual, se exhumaron fosas y construyeron monumentos conmemorativos ${ }^{25}$. La nueva historiografía y memoria trasnacional fue fundamental para que el interés por la memoria se consolidase en el año 2000, especialmente con el nacimiento del Movimiento por la Recuperación de la Memoria Histórica de mano de asociaciones de familiares que luchaban por el reconocimiento de las víctimas y demandaban justicia social. Y aquí el factor

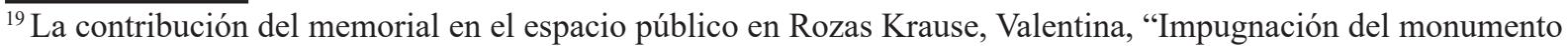
tradicional: cuatro críticas aplicadas a Santiago y Buenos Aires", en Guixé i Coromines, Jordi (ed.), Past and Power... op. cit., pp. 445-461.

${ }^{20}$ Una visión comparada en Águila, Gabriela y Luciano Alonso (coords.), Procesos represivos y actitudes sociales. Entre la España franquista y las dictaduras del Cono Sur, Buenos Aires, Prometeo, 2013.

${ }^{21}$ Ley 46/1977 de 15 de octubre, de Amnistía, Boletín Oficial del Estado, número 248, 17 de octubre 1977.

${ }^{22}$ Algunos historiadores han destacado que la memoria social en España se fundamentó sobre un "deseo de olvido" para superar un pasado traumático y favorecer la convivencia, caso de Sevillano Calero, Francisco, "La construcción de la memoria y el olvido en la España democrática", Ayer, 52 (2003), 297-319. La crítica de la instrumentalización de la memoria en pro de la reconciliación nacional durante la Transición, en Pérez Serrano, Julio, "Experiencia histórica y construcción social de las memorias. La Transición española a la democracia”, en Pasado y Memoria. Revista de Historia Contemporánea, 3 (2004), pp. 93-124. Una síntesis desde la "desmemoria" al "estallido memorialista" en Ortiz Heras, Manuel, "Memoria social de la Guerra Civil: La memoria de los vencidos, la Memoria de la frustración", en Historia Actual online, 6 (2006), pp. 179-198. En el debate historiográfico han destacado las posturas enfrentadas de quienes acusan a la Transición de imponer políticas de olvido, como Espinosa, Francisco, Contra el olvido: historia y memoria de la guerra civil, Barcelona, Crítica, 2006, pp. 171-204; y los que la definen como un periodo de amnistía en pro de la reconciliación, como Juliá, Santos, Elogio de historia en tiempo de memoria, Madrid, Marcial Pons, 2011. Una buena síntesis sobre la memoria histórica y sus discursos políticos como fenómeno social y cultural del presente, que responde a la coyuntura de los ochenta en toda Europa, aunque en España irrumpe en los noventa, en el artículo de Ruiz Torres, Pedro, "Los discursos de la memoria histórica en España", en Hispania Nova, 7 (2007), pp. 1-30. «http://hispanianova.rediris.es/7/dossier/07d001.pdf» [consultado el 23 de enero de 2017]. Sobre este debate Reyes Mate concluye que entre las primeras obligaciones de la democracia está, precisamente, el deber de Memoria. Véase Mate, Reyes, La herencia del olvido, Madrid, Errata Nature, 2009, p. 175, remitimos al capítulo 7, "Tierra y huesos. Reflexiones sobre la historia, la memoria y la «memoria histórica»". Por su parte Pérez Garzón y Manzano han insistido en abordar la irrupción y gestión de la memoria y su relación con la historia y el poder, en Pérez Garzón, Juan Sisinio y Eduardo Manzano, Memoria histórica, Madrid, Consejo Superior de Investigaciones Científicas y Los Libros de la Catarata, 2010.

${ }^{23}$ Benchili, Iman, España y Portugal: las políticas de memoria entre consenso y ruptura, trabajo fin de máster, Universidad de Salamanca, 2014. «http://gredos.usal.es/xmlui/handle/10366/123440» [consultado el 23 de marzo de 2016].

${ }^{24}$ Erice, Francisco, Guerras de la memoria y fantasmas del pasado. Usos y abusos de la memoria colectiva, Oviedo, Eikasia, 2009, pp. 358-369.

${ }^{25}$ Bernecker, Walter y Sören Brinkmann, Memorias divididas. La guerra civil y el franquismo en la política española (1936-2008), Madrid, Abada, 2009, p. 245.
} 
generacional fue clave favoreciendo al fin la aprobación de la Ley 52/200726, popularmente conocida como Ley de Memoria Histórica. Una ley centrada principalmente en la retirada de símbolos franquistas y en indemnizar con limitadas compensaciones económicas, pero que deja al margen las reparaciones judiciales y quedan impunes los victimarios. Esta ley que ha sido y es elemento continuo de discordia experimentó el arrinconamiento en 2013 por el gobierno del Partido Popular, que anuló los presupuestos para la exhumación de fosas comunes y eliminación de símbolos franquistas, desestimando también las propuestas realizadas por la Comisión de Expertos creada a instancias de la misma, sobre el futuro del controvertido monumento del Valle de los Caídos. No obstante, a partir de 2015, con los cambios de gobierno de algunos ayuntamientos y la entrada de nuevos partidos políticos en la gestión municipal y autonómica, se han reavivado los debates sobre el cumplimiento de la Ley de Memoria. Pero la construcción de espacios conmemorativos, la conservación del patrimonio memorial e incluso las exhumaciones de las victimas republicanas sigue relegada, fundamentalmente, al ámbito autonómico y local y al asociacionismo civil (fundamental agente en el modelo de memorialización español), evidenciándose la falta de apoyo e interés por parte del Estado español que, como denuncia Cristina Sánchez, "permite los actos performativos o simbólicos, pero no la creación de estructuras más permanentes, como centros de interpretación" $"$. En perspectiva, comparada con otros países (caso de Alemania, Argentina, Chile y Uruguay, por ejemplo) España experimenta en el terreno de la memoria y de su reconocimiento público uno de los panoramas más deficitarios de nuestro tiempo ${ }^{28}$.

\subsection{Canalizar la memoria}

Las representaciones de la memoria son cada vez más variadas y, por ende, los medios conductores del mensaje presentan distinta dimensión o capacidad para transmitir valores, comunicar, legar la memoria y resistir al paso del tiempo. Señalamos a continuación algunos de los principales formatos y soportes para la canalización de la memoria:

\footnotetext{
$\overline{{ }^{26} \text { Ley 52/2007, de }} 26$ de diciembre, por la que se reconocen, amplían derechos y se establecen medidas en favor de quienes padecieron persecución o violencia durante la guerra civil y la dictadura, Boletín Oficial del Estado, número 310, 27 de diciembre 2007.

${ }^{27}$ Sánchez-Carretero, Cristina, "Patrimonialización de espacios represivos. En torno a la gestión de los patrimonios incómodos en España”, en Ortiz García, Carmen (coord.), Lugares de represión, paisajes de la memoria: aspectos materiales y simbólicos de la cárcel de Carabanchel, Madrid, Catarata, 2013, p. 29. «http://digital.csic.es/ bitstream/10261/98649/1/patrimonializacion_espacios_represivos_Sanchez.pdf» [consultado el 23 de marzo de 2016].

${ }^{28}$ Como se denuncia en González Martínez, Carmen y Encarna Nicolás Marín, "Perspectivas historiográficas en las Transiciones políticas contemporáneas a la democracia”, en González Madrid, Damián (Coord.), El Franquismo y la Transición en España. Desmitificación y reconstrucción de la memoria de una época, Madrid, Los Libros de la Catarata, 2008, pp. 201-22.
} 
a) Internet: su accesibilidad favorece la difusión de memorias individuales y colectivas, establece redes y puentes interculturales, facilitando la divulgación e internacionalización de la memoria constituyendo un espacio cómodo para generar debates e intercambio de opiniones ${ }^{29}$. En algunos casos es utilizado como refuerzo complementario o sucursal de una entidad ya existente, como en el caso de páginas web y aplicaciones móviles que proporcionan más información al usuario sobre la institución en cuestión; en otros se muestra como único elemento de trasmisión (por ejemplo, museos virtuales), recopilando datos y contenidos que de otro modo sería imposible reunir y exponer. Pese a las ventajas que los blogs y redes sociales ofrecen como medios generadores de opinión, estos no tienen el impacto suficiente para hacer perdurar o legitimar una visión de la historia, tendiendo a desaparecer en un entorno en constante actualización: el hipertexto y la sobreinformación confunden las fuentes originales; la multiplicidad de discursos, lo artificioso y lo real, la distancia del espacio virtual y el anonimato imposibilitan enlaces sensitivos y empáticos que calen en los internautas. Por otro lado, los medios informáticos permiten almacenar, recuperar y compartir la memoria de un modo ágil e instantáneo y ofrecen un medio para salvaguardar el patrimonio en delicado estado de conservación por medio de su digitalización y difusión (fotografía, vídeo, archivo oral...), pero la cantidad, velocidad y escasa calidad de lo que generamos imposibilita a la par conservarla de manera coherente y selectiva, ignorando el riesgo de pérdida o la fragilidad y obsolescencia de los soportes informáticos para su posterior conversión ${ }^{30}$.

b) Placas y listas: dentro de los espacios urbanos son el medio más recurrido de trasmisión de la memoria, proporcionan información reducida, generalmente nombres o fechas (petición común entre los familiares de víctimas que buscan de este modo devolverles la identidad y dignidad). Pueden aparecer agrupadas, buscando orden y equidad inscritas sobre muros o monolitos o aisladas, limitándose a situar el suceso y ubicar al espectador en el hecho histórico. No es raro encontrar cruces y otros elementos multiplicados, legados de los cementerios, funcionando como recuerdo y sentimiento de conmemoración colectivo. Pero como argumentan Macarena Silva y Fernanda Rojas ${ }^{31}$, con dudosa efectividad, ya que la información tan señalada y particular reduce la memoria a un punto en el mapa o a un dato falto de experiencia o significado que redunde en el aprendizaje del espectador.

c) Representaciones artísticas: diferenciamos el memorial clásico del contemporáneo ${ }^{32}$. El primero tiene un objetivo más conservador haciendo uso de la escultura y la figuración

\footnotetext{
${ }^{29}$ Solanilla-Demestre, Laura, "Sociologando: Internet como herramienta de recuperación de la memoria de la Guerra Civil Espanola”, en Boletín Cientifico Sapiens Research, vol. 2, 2 (2012), pp. 46-53. «https://dialnet. unirioja.es/descarga/articulo/3973511.pdf» [consultado el 22 enero de 2017].

${ }^{30}$ Santacana, Joan y Francesc Xavier Hernández Cardona, Museos de historia ... op. cit., pp. 41- 42.

${ }^{31}$ Silva, Macarena y Fernanda Rojas, "El manejo urbano-arquitectónico de la memoria urbana traumatizada", en Ciudad y memorias: desarrollo de sitios de conciencia en el Chile actual, Santiago de Chile, Corporación Parque por la Paz Villa Grimaldi, 2011, p. 81. «http://villagrimaldi.cl/wp-content/uploads/2011/11/17531_Ciudad_y_ Memorias Villa Grimaldi.pdf» [consultado el 25 de marzo de 2016]

${ }^{32}$ El desarrollo y significación del monumento memorial en Escribano Gonzálvez, Elena, "Retos y singularidad del memorial", en González Madrid, Damián et al. (coords.), La Historia, lost in translation? Actas del XIII Congreso
} 
por medio de materiales permanentes, con la intención de generar una marca definitiva. Los contemporáneos destacan por el uso de lenguaje más intelectual y abstracto donde se reitera el uso de conceptos como el tamaño, la fragmentación, el vacío, la repetición, el uso o ausencia de luz o la naturaleza, comúnmente utilizados para invocar el dolor, la pérdida, el número de víctimas, etc. en variedad de formatos, incluso efímeros. En este campo destaca la corriente "contramonumentalista", desarrollada por artistas que proponen un "antimonumento" para tratar, precisamente, la irrepresentabilidad que supone el trauma, apostando por lenguajes críticos, como intervenciones, performances, etc., a modo de protesta de la estética tradicional ${ }^{33}$. Obras polémicas que invitan a la reflexión como expresa el artista alemán Horst Hoheisel, "los monumentos están vivos mientras se discute sobre ellos. Una vez instalados, esas moles de mármol, bronce o concreto, por más grandes que sean se vuelven invisibles, se olvidan. Y sólo vuelven a estar vivos cuando se empieza a pensar en su demolición" ${ }^{\text {"34 }}$. Pero este tipo de representaciones artísticas simplifican el suceso a metáforas o símbolos transmitiendo los hechos de un modo indefinido y subjetivo, pudiendo quedar la historia en un hecho ambiguo, por lo que el virtuosismo del artista o arquitecto al emplear determinados lenguajes simbólicos es a su vez susceptible de juicio.

d) La musealización: ofrece una reflexión histórica por medio de la patrimonialización de diferentes espacios. Hablamos de "Museo" de un modo general entendiendo tanto los lugares que funcionan como soportes de enunciación que pueden, o no, hacer referencia al espacio con o sin colección, como los centros de interpretación o centros de visitantes que conservan y preservan indistintamente patrimonio material (objetos, archivos, documentos, etc.) o inmaterial (paisajístico, oral, etc.) bajo diferentes estructuras narrativas, recorridos cronológicos o anacrónicos, lineales o temáticos, con la intención de generar una experiencia más completa. Las nuevas tecnologías de la información y comunicación, el uso de dioramas, maquetas, vitrinas o instalaciones interactivas invitan al espectador a profundizar y absorber el discurso e interactuar con el museo. En ocasiones la complejidad o enfoque del tema y la descontextualización de los objetos provocan desacuerdos y desaprobación por parte de los asistentes; no obstante, el potencial que encierra la musealización para rescatar, conservar y transmitir la historia y la memoria colectiva convierten a este canal en el medio más completo, característica esta que invita a profundizar en este género y en las posibilidades tan heterogéneas que ofrece, como exponemos a continuación.

\footnotetext{
de la Asociación de Historia Contemporánea, Cuenca, Ediciones de la Universidad de Castilla-La Mancha, 2017, pp. 885-893.

${ }_{33}$ Martínez Rosario, Domingo, La obra de arte como contramonumento. Representación de la memoria antiheroica como recurso en el arte contemporáneo, Tesis doctoral, Universitat Politècnica de València, 2013, p. 138. DOI: 10.4995/Thesis/10251/34786. «https://riunet.upv.es/handle/10251/34786» [consultado el 22 de marzo de 2016]. ${ }^{34}$ Malosetti Costa, Laura, "La polémica de los monumentos por la memoria", en Clarín, 24 de julio de 2004. «http://edant.clarin.com/suplementos/cultura/2004/07/24/u-800082.htm» [consultado el 23 de marzo de 2016].
} 
2. Tratamiento de la memoria en los museos

La exposición de la barbarie y la guerra queda justificada en las nuevas museografías por la necesidad de preservar y conservar espacios patrimoniales que fueron escenario de las tragedias así como archivos, objetos y documentos resultado de estas herencias incómodas como herramientas de legitimación y prevención, que puedan transmitir lo ocurrido y ofrezcan al visitante una visión crítica, didáctica e incluso emocional ${ }^{35}$. Pero son tantos los lugares para la transmisión de conocimiento histórico y revalorización del patrimonio y la memoria que se hace muy difícil, sin agruparlos, hablar de sus diferencias. En este sentido y para dilucidar el caso español, señalamos y caracterizamos algunos modelos de musealización ${ }^{36}$ que dan tratamiento a la memoria nacional.

a) Museo histórico militar: ocupados en la preservación del patrimonio principalmente armamentístico, estos museos se alzan como un instrumento más del Estado para la exaltación de los valores patrióticos y glorificación militar. Con la llegada de la democracia se hace un esfuerzo por desligar aquellos intereses ideológicos y bélicos orientando su museografía hacia un carácter didáctico y científico, aunque en el caso de España sin demasiada autocrítica. Dedican generalmente alguna parte bastante residual de su conjunto expositivo para explicar su intervención en los sucesos más trágicos y violentos de la historia, pero sin mencionar a las víctimas, destacando el papel de algún cuerpo militar o la aplicación de algún artefacto. Al respecto es interesante el análisis de Zoé de Kerangat sobre el Museo de Historia en Cataluña, en el que destaca la neutralidad, recelo y minimalismo que adopta el museo al tratar la Guerra Civil española y la imposibilidad de estas instituciones por "mostrarse abiertamente políticas a la hora de aceptar la culpa y la responsabilidad"37.

Otro caso es el Museo del Ejército con sede en Toledo (anteriormente emplazado en Madrid) que durante décadas ha participado del discurso propagandístico del régimen franquista, permaneciendo intacto durante la democracia. En el año 2003 fue trasladado polémicamente al Alcázar de Toledo, lugar connotado y casi mitificado por su implicación durante la Guerra Civil. En el año 2007 y a instancias de la Ley de la Memoria Histórica, se solicitó un cambio sustancial de su contenido que proporcionase una visión más completa de la historia militar de España en el contexto de su evolución política y cultural; cambio que no vio la luz hasta el año

\footnotetext{
${ }^{35}$ En la batalla por no olvidar los horrores del pasado, su conservación y musealización, véase Romero, Margarita et al., Acceso público a la memoria. El rol de los archivos testimoniales en la democratización de las sociedades postdictatoriales, Santiago de Chile, Corporación Parque por la Paz Villa Grimaldi e Instituto de la Comunicación e Imagen de la Universidad de Chile, 2009.

${ }^{36}$ Análisis fundamentado en el estudio de Hernández Cardona, Francesc Xavier, "Conflictos contemporáneos, estrategias de musealización crítica", en Mnemòsine, 1 (2004), pp. 15-33. «http://www.museoyterritorio.com/pdf/ museoyterritorio04-8.pdf» [consultado el 25 de marzo de 2016].

${ }^{37}$ De Kerangat, Zoé, "Réhabiliter leur mémoire? Représentations des victimes de la Guerre Civile et du franquisme dans les musées d'Espagne", en Nuevo Mundo Mundos Nuevos, (2015), p. 22. DOI: 10.4000/nuevomundo.67836. «http://nuevomundo.revues.org/67836» [consultado el 24 de marzo de 2016].
} 
2010, cuando finalmente fue inaugurado como nuevo museo del Ejército. Y pese a tener desde entonces un discurso enfocado a mostrar la democracia y mejoras didácticas y audiovisuales, en lo que concierne a la historia del siglo xx y según critica José María Lanzarote, continúa vinculado a algunas interpretaciones sesgadas a la hora de encajar el periodo de la Segunda República, justificando el levantamiento militar ${ }^{38}$.

El público principal de estos museos es, junto al turista, el escolar, apunte que invita a reflexionar sobre su responsabilidad con la historia y el papel tan fundamental que este tipo de museos desempeñan como herramienta educativa.

b) Museos monográficos y Centros de interpretación: elaboran su discurso desde un mismo punto de vista o episodio concreto de la historia, mostrando especial interés por la divulgación y la investigación histórica, y por impulsar la localización, recuperación y conservación de espacios del patrimonio integral memorial. Ejemplo de esta categoría es el Museo del Exilio en Cataluña, un museo de nueva planta en torno al exilio republicano de 1939 y que además señaliza y crea itinerarios sobre los caminos del exilio para su posterior visita. También aquí podemos incluir el Museo Refugio de la Guerra Civil en Cartagena, o Centros de Interpretación como las trincheras en los Monegros, la ruta por los Espacios de la Batalla del Ebro o la Batalla del Jarama. Por lo general se trata de iniciativas emprendidas por las administraciones locales o autonómicas e incluso privadas (en ocasiones sin apoyo estatal) con la intención de construir o reactivar la identidad local o autonómica.

c) Museo por la Paz o los DDHH: planteados como elementos claros para la educación de valores cívicos y la reflexión del conflicto. Analizan la tragedia estudiando las causas y asociándola a conflictos contemporáneos, animando al espectador a considerar y meditar sobre cuáles son los recursos de los que dispone la sociedad para su prevención. Por último, deben superar la inercia a convertirse en un mero agente político, centrándose más en aspectos éticos y morales universales. Una muestra de esta categoría es el Museo de la Paz de Gernika, único museo de la Paz en España dedicado al bombardeo y destrucción de la ciudad por aviones alemanes e italianos bajo el mando franquista en 1937 y con un espacio dedicado al terrorismo y a la violencia en el País Vasco.

d) Museos conmemorativos: son los centros emblemáticos de la memoria, baluartes contra la guerra y la injusticia, y pueden situarse sobre edificios de nueva planta o sobre antiguos espacios colaboradores del trauma, como antiguas prisiones o campos de concentración o exterminio. Representan la lucha por las libertades consagrándose como una herramienta indispensable que reúne los componentes histórico y memorial: el primero, el histórico, presente en las condiciones intrínsecas del espacio, al tratarse de un testimonio irrefutable de la barbarie y el segundo, el memorial, por convocar en la misma superficie un llamamiento a la solemne reflexión, homenaje y recuerdo de los que ya no están, acompañándose de manifestaciones

\footnotetext{
${ }^{38}$ Lanzarote Guiral, José María, "National Museums in Spain: A History of Crown; Church and People", en Aronsson, Peter y Gabriella Elgenius, Building National Museums in Europe 1750-2010, Linköping University Electronic Press, 2011, pp. 871-874. «http://www.ep.liu.se/ecp/article.asp?issue=064\&article=035» [consultado el 24 de octubre de 2016].
} 
artísticas, además de otros espacios como archivos y bibliotecas que aportan al espectador más información respecto al discurso y pasado histórico traumático. La mayoría de estos museos apuesta por una experiencia pedagógica y emocional. En España, sin embargo, los intentos de resignificar democráticamente el controvertido monumento del Valle de los Caídos hasta el momento han sido vanos: construido con mano de obra de presos políticos durante el franquismo para perpetuar la victoria franquista en la Guerra Civil y honrar a los "Caídos por Dios y la Patria", se convirtió también en lugar de enterramiento para los caídos del bando republicano tras el saqueo de fosas y desplazamiento de cuerpos al complejo sin conocimiento de las familias. El Valle de los Caídos cuenta además con una Basílica donde descansan los restos del dictador Francisco Franco y del fundador de Falange, José Antonio Primo de Rivera, un motivo más de disputa que obstruye cualquier posibilidad de consenso y reconciliación entre las posturas enfrentadas sobre su futuro y la apuesta, o no, por una nueva significación memorial del complejo ${ }^{39}$. La Basílica está comunicada con una abadía benedictina compuesta por dos edificios: el propio monasterio y una escolanía que fue Centro de Estudios Sociales hasta 1982, que alberga en su archivo los datos de los cuerpos allí enterrados. Este espacio continúa hoy sin encontrar el consenso necesario que lo encamine hacia una representación memorial democrática e integral, sigue sin cumplirse la Ley de Memoria Histórica: hasta el momento toda iniciativa de cambio sigue inmóvil, tan petrificada como el mármol que decora este complejo arquitectónico y escultórico.

Dentro de las formas de musealización de la memoria la categoría de museos conmemorativos ha conseguido expandirse y tener una gran proyección generando una tendencia cultural que ha logrado imponerse en todo el mundo. Podríamos mencionar numerosos ejemplos como el de Caen, el Museo de la Masacre de Nanjin, el Museo del Genocidio en Kigali, el Museo a la Víctimas del Comunismo en Rumanía, incluso sucesos trágicos más recientes como el Memorial 9/11 de Nueva York. Pero ¿qué los hace singulares?

\section{El museo conmemorativo}

\subsection{Características y fines}

En las siguientes líneas enumeramos algunas características propias de estos espacios ${ }^{40}$ que, si bien por sí solas no son excluyentes respecto a otros museos de historia, combinadas creemos que configuran un patrón de la nueva tendencia cultural:

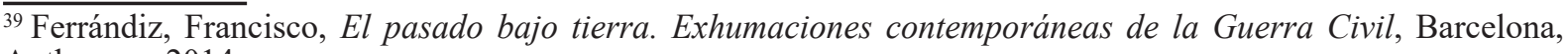
Anthropos, 2014.

${ }^{40}$ Ampliando el estudio de Velázquez Marroni, Cintia, "El museo memorial...” op. cit., p. 28.
} 
- Objeto histórico y documento del pasado. Tienen la misión de investigar, conservar y ofrecer las fuentes precisas con relación a ese pasado que aún atora a la sociedad para que esta se desarrolle bajo un marco justo. En algunos casos se trata de construcciones de nueva planta y, en otras, toman como soporte edificios o espacios vinculados a la tragedia como lugar de enunciación de la memoria. Los discursos museísticos se basan más en los hechos que en las colecciones no obstante estas tienen un alto poder narrativo y dan testimonio de lo ocurrido $^{41}$. Por ello abastecen su fondo con documentos, fotografías, piezas originales que son inventariados, clasificados y documentados.

- Espacio de reflexión y conciliación. Michael Lazzara habla de una "museología crítica" y destaca que el museo ha de funcionar como soporte de diferentes contenidos, servir de punto de encuentro y discusión, "darle figuración al recuerdo y crear mecanismos de transmisión de sus significaciones" ${ }^{\prime 2}$. Entendemos que es una herramienta que lidia con los desacuerdos entre memorias individuales y colectivas y otros conflictos respecto al contenido que allí se expone. Enseña al espectador sobre lo que debe recordar y el propósito, estimulando consideraciones morales para habilitar una memoria democrática.

- Reconstrucción y terapia. Entre sus fines destacan restablecer el trauma social poniendo en valor el pasado y devolver la identidad a una sociedad que se enfrenta a su vez a un proceso de duelo mediante herramientas pedagógicas que redunden en aspectos psicológicos. Esto explica, la existencia de un público fidelizado que mantiene vínculos estrechos y sensitivos con el memorial, que no solo se exponen a nuevos aprendizajes, sino que además interpretan el contenido experimentando el recuerdo y reviviendo el pasado.

- Acogen actividades políticamente significativas. Las plataformas ciudadanas por la recuperación, conservación y estudio de la memoria, comisiones de la verdad y ONGs que respaldan y luchan abiertamente por los procesos de investigación enfocados al enjuiciamiento de culpables y/o al apoyo de las víctimas encuentran en este espacio un lugar para impulsar sus intereses conmovidos por las pulsiones políticas del momento.

- Conmemoran a víctimas que han perdido la vida injustamente, un sacrificio en masa como define Paul Williams ${ }^{43}$ cuya historia se presta a cierta tendencia a la mitologización debido a su cualidad dramática.

- Reunir espacios lúdicos y sacros. Son lugares de exhibición que atraen el interés del público también con fines turísticos o de esparcimiento y a la par albergan, dada su temática, lugares sagrados, vinculados o no a la religión, pero sí de culto y recogimiento.

\footnotetext{
${ }^{41}$ Arnold de Simine, Silke, Mediating memory in the museum: Trauma, empathy, nostalgia, Houndmills, Palgrave Macmillan, 2013, p. 10.

${ }^{42}$ Lazzara, Michael, "Dos propuestas de conmemoración pública: Londres 38 y el Museo de la Memoria y los Derechos Humanos (Santiago de Chile)", en A Contracorriente, vol. 8, 3 (2011), p. 86. «http://www.ncsu.edu/ acontracorriente/spring_11/articles/Lazzara.pdf» [consultado el 22 de marzo de 2016].

${ }^{43}$ Williams, Paul, Memorial museums: the global rush to commemorate atrocities, Oxford, Berg Publisher, 2007, p. 8 .
} 


\subsection{Retos y limitaciones}

Son muchas las cuestiones suscitadas en torno a la relación museos-memoria, y por tanto muchos los aspectos que precisan de una atención pormenorizada para su idónea comprensión. En esta línea de investigación consideramos necesario exponer algunos de los retos y limitaciones más frecuentes de los museos conmemorativos:

a) La ubicación: una tarea difícil en el asentamiento de obras mnemónicas y edificios construidos ex profeso como lugares de enunciación e inscripción es la de encontrar un lugar apropiado donde emplazarlas. Escoger un lugar transitado o ya marcado puede arrinconar la obra y ubicarla en zonas estériles, en desuso o alejadas del núcleo de población puede hacerla caer en la indiferencia. También la carga política y las connotaciones negativas, al tratarse de lugares auténticos y perturbadores como cárceles o campos de concentración, abocan a este patrimonio memorial al abandono y la destrucción, ya sea por razones ideológicas o por la disimulada consecuencia del desarrollo urbano. En este aspecto España desatiende la memoria de lugares trágicos o bien los condena al abandono, además de incumplir su legislación respecto a la retirada de símbolos de exaltación de la Guerra Civil española y la dictadura. En otras ocasiones se apuesta por la conservación y musealización de estos espacios y es entonces cuando surge el desafío de la resignificación: redirigir su significado y otorgarles un nuevo sentido y valor memorial para que la sociedad los admita y reconozca como elementos identitarios ${ }^{44}$.

b) Instrumentalización: Los derechos de la sociedad sobre el pasado y la memoria están supeditados a ser parte de las negociaciones entre los distintos poderes políticos. Los gobiernos establecen o derogan legislaciones y otorgan o suprimen subvenciones convirtiendo a las políticas públicas sociales y culturales en algo pobre y transitorio, como parte de una estrategia. El olvido y la negación de la historia se manifiestan, en el caso de España, en el bloqueo de documentación diplomática relacionada con la Guerra Civil y el franquismo, o en el intencionado revisionismo con el que instituciones y organismos con dominio legitimador han sometido a la historia, por lo que no es de extrañar que la sociedad termine cediendo a la construcción de memorias etnocentristas que deshistorializan a las víctimas si hay fines lucrativos o si se extraen ciertos beneficios sobre "parecer moral"

c) Conexión y red: en España no sorprende en absoluto la ausencia de proyectos de memoria o instauración de fechas conmemorativas a nivel nacional referentes al pasado trágico que dejen constancia o refuercen nuestra identidad porque no hay contexto político ni tradición memorial que así lo permita (carecemos de un museo de historia nacional). Lo común, sin

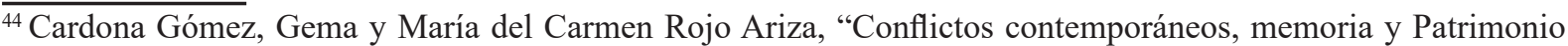
Mundial: una relación problemática. El caso de los espacios patrimoniales de la Guerra Civil Española”, en Castillo, Alicia (ed.), Actas del Primer Congreso Internacional de Buenas Prácticas en Patrimonio Mundial: Arqueología, Madrid, Universidad Complutense, 2011, pp. 218-234. «http://www.academia.edu/download/30472692/Rojo_ Cardona_patrimonio_negativo_Menorca_patrimonio_mundial_2012.pdf» [consultado el 23 de marzo de 2016]. ${ }^{45}$ Sobre los principios morales, Glover, Jonathan, Humanidad e inhumanidad: una historia moral del siglo XX, Madrid, Cátedra, 2001, pp. 44-53.
} 
embargo, es la desorganizada y desconectada multiplicidad de discursos puntuales y aislados desde organismos privados y locales y la falta de un discurso objetivo central y coherente que no interfiera en las circunstancias o idiosincrasia de cada ámbito territorial convirtiendo, así, a la memoria en una memoria colectiva y heterogénea, compleja y diversa, que permita enriquecerse de estas diferencias territoriales, que ayude al país a identificarse con su historia y pasado nacional, como podría proporcionar el Valle de los Caídos o el olvidado y aparcado proyecto Memorial por la Paz de Teruel ${ }^{46}$.

d) Desacuerdos y memoria selectiva: como sucedió con el diseño del monumento a los Veteranos de Vietnam en Washington, al que gran parte de los excombatientes militares rechazaron por antiheroico y orientado a la muerte, culpándolo de abrir una grieta entre los que deseaban conciliarse con el pasado reconociendo su culpa y los que preferían orientarlo a la glorificación de los militares caídos ${ }^{47}$, la falta de representatividad y reconocimiento de algunos colectivos genera situaciones de fragmentación y desacuerdo. Diferenciamos monumentos conmemorativos, comunitarios y públicos, que son consensuados y que tienen en cuenta la visión de las víctimas, artistas, agentes culturales, etc. y los fragmentados, que suelen provocar tensiones entre "la necesidad de recordar para no repetir" y su contraria, "es mejor no desenterrar el pasado".

e) Enseñanza: se echa en falta un elemento vertebrador que integre el discurso del espacio museológico con el mundo académico (escolar y universitario). Los memoriales no deben ser solo un impedimento para el olvido, sino que deben facilitar la trasmisión de memoria manteniendo la perspectiva histórica y ofreciendo un espacio de estudio que impulse la investigación sobre lo ocurrido, reflejando el interés por continuar aprendiendo y generar conciencia a las nuevas generaciones. Los museos son una alternativa que complementa la enseñanza, emprendiendo proyectos pedagógicos que favorecen la experiencia, desarrollando actividades, talleres y cursos especializados para cada tipo público.

f) Saturación: la obsesión contemporánea por conservarlo todo y hacerlo "memorable"48 entraña el peligro de distorsionar la historia congelando el recuerdo. La masificación y construcción acelerada de memoriales y su mercantilización y utilización como arma política ha perjudicado a las familias de las víctimas invisibilizando las demandas de justicia. Fruto de la globalización encontramos lugares tergiversados hacía el falseamiento histórico; homogenizados, sitios históricos que abandonan su tarea de preservar los restos y nos muestran, en cambio, "la reconstrucción de algo que efectivamente existió y pudo haberse conservado, pero que fue absurdamente destruido", lugares asépticos, rodeados de souvenir y sobreinformación

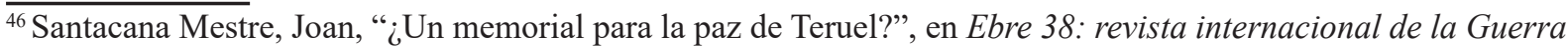
Civil, 1936-1939, 4 (2010), pp. 257-265. «http://dialnet.unirioja.es/descarga/articulo/4851806.pdf» [consultado el 11 de marzo de 2016].

${ }^{47}$ Vicente, Henry, "El reverso de lo monumental. El Memorial de los Veteranos de Vietnam", en Cuaderno de Notas, 11 (2007), pp. 1-24. «http://polired.upm.es/index.php/cuadernodenotas/article/view/843/864» [consultado el 22 de marzo de 2016].

${ }^{48}$ Para profundizar sobre este tema: Regine, Robin, La Memoria Saturada, Buenos Aires, Waldhuter, 2012.
} 
pedagógica, con reproducciones que suprimen cualquier asociación emocional con el recuerdo original y enmascaran el horror, como señala Peter Vergo ${ }^{49}$. Es un deber reflexionar sobre la explotación de fenómenos crecientes como el "tanaturismo", que se nutre de la fascinación humana, anhelando encontrar una experiencia auténtica en los lugares relacionados directamente con el horror ${ }^{50}$.

g) Espectacularización: los discursos que buscan atraer flujos de turismo y desarrollo local pueden repercutir erróneamente en una pérdida de intencionalidad y de rigor histórico: escenografías que inciden en estereotipos y abusan de exhibiciones morbosas banalizan la memoria y por tanto distancian al público del mensaje principal. La directora de programas del museo judío de Berlín, Cilly Kugelmann, pone de manifiesto su disconformidad sobre el abuso de estas estrategias que, según su opinión, terminan convirtiendo a la memoria en algo pueril y populista y se justifican bajo la falsa premisa de que el público es ignorante y necesita refuerzos extra ${ }^{51}$. Por su parte Zoé de Kerangat critica la representación de las víctimas en los discursos museográficos, la generalidad de crear personajes ficticios que guían al visitante con narraciones que aúnan distintos testimonios reales, como sucede con la voz que nos acompaña en la visita al Museo de la Paz de Gernika ${ }^{52}$ y que encarna así el papel de una víctima universal "victimizada" y simbólica; estereotipo que puede confundir al espectador sobre la existencia real de esa historia.

\section{Conclusión}

Esta investigación sobre la significación del memorial y sus principales formatos y canales demuestra que su construcción como elementos conmemorativos y, especialmente, el de los museos como herramientas culturales sirve para satisfacer la necesidad social de respeto y reconocimiento a las víctimas, propiciando también la rehabilitación del trauma social. No obstante la experiencia museística ya acumulada propicia evitar, por medio de la intermediación cultural, que los memoriales caigan en la indiferencia y se conviertan en espacios limitados a inducir la nostalgia y a exhortar la paz mundial. La construcción de monumentos y museos

\footnotetext{
${ }_{49}$ Bolaños, María, La memoria del mundo: cien años de museología (1900-2000), Gijón, Ediciones Trea, 2002, pp. 320-323.

${ }_{50}^{50}$ Knudsen, Britta Timm, "Thanatourism: Witnessing difficult pasts”, en Tourist Studies vol. 11, 1 (2011), pp. 5572. DOI: https://doi.org/10.1177/1468797611412064. «http://web.mnstate.edu/robertsb/390/Thanatourism\%20 Witnessing\%20Diffcult\%20Pasts.pdf» [consultado el 22 de octubre de 2016].

${ }^{51}$ Sánchez, Matilde, "Los museos y el porvenir de la memoria", en Clarín, 16 de marzo de 2010. «http://edant. revistaenie.clarin.com/notas/2010/03/16/_-02160064.htm» [consultado el 22 de marzo de 2016].

${ }^{52}$ De Kerangat, Zoé, "Réhabiliter leur..." op . cit., p. 31.
} 
memoriales no debe convertirse en un modo de privatizar la historia, como tampoco dejar que la especificidad del hecho se subordine a cuestiones éticas y morales genéricas.

En esta línea discursiva, y en contraposición a canales menos autónomos y erosionables a la opinión pública, este artículo muestra los distintos tipos de espacios museográficos para la transmisión de la historia y la memoria, explorando qué diferencias y posibilidades ofrece el museo como estrategia cultural y artística de revaloración del patrimonio e instrumento de justicia social, y más concretamente el museo conmemorativo, al adquirir este una actitud política mayor ya que deben ocuparse de la interpretación y contextualización de un modo crítico, sin olvidar el propósito simbólico de reparación y de representación y homenaje a las víctimas.

El estudio muestra cómo diferentes experiencias históricas se traducen en diversos modelos de promoción de memoriales tanto los levantados por la acción de los movimientos de familiares y asociaciones memorialistas (que exigen responsabilidades y compromiso a sus respectivos gobiernos), como los construidos por los propios Estados como instancia estatal de regeneración del país y para consolidar la identidad democrática nacional durante las coyunturas transicionales y post-dictatoriales, al tiempo que para ratificar, con el patrimonio memorial, la defensa de los DDHH.

Por lo que respecta a España y desde una perspectiva comparada resalta la insuficiencia memorial en nuestro país en torno a un marco y modelo estatal comprometido, que ayude tanto a la identificación del pasado más trágico como a la puesta en marcha de una política memorial que posibilite el aprendizaje democrático y el homenaje cívico a los que ya no están. Un modelo que fomente y mantenga, con compromiso político y dignidad, espacios memoriales que, pese a su naturaleza siempre controvertida, aboguen por la reconciliación y el consenso, evitando discursos hegemónicos o excluyentes que impidan la construcción de una ciudadanía democrática, uno de los rasgos más singulares y positivos de los memoriales. 